[Aus dem hygienischen Institut der Unirersität Breslau.]

\title{
Ein Beitrag zur Verbreitung der säurefesten Bacillen.
}

\author{
Von \\ Stabsarzt Dr. Herr in Posen. \\ früherem Assistenten sm Inatitut.
}

Durch die Arbeit von Möller ${ }^{1}$ wurde zuerst das Vorkommen von säurefesten Bacillen auf Gräsern und im Kuhmist festgestellt. Es lag jedoch der Gedanke nahe, dass nicht nur auf den ron ihm angegebenen Gräsern und im Kuhdünger diese Bacillen zu finden sein würden, sondern dass ihnen ein viel grösseres, ja vielleicht ein sehr verbreitetes Vorkommen zusteht. Man könnte sogar an einen gewissen Kreislauf denken, insofern die Bacillen mit dem Futter in den Darm des Thieres, von hier durch den Dünger auf die Felder und so wieder auf die Futtergräser gelangen können. Dann aber müsste man diese Bakterien auch in der Ackererde häufig finden. Die Angaben Chauveau's², der Tuberkelbacillen in Regenwürmern gefunden haben will, lassen sich vielleicht dahin deuten; denn dass es sich in diesem Falle um Tuberkelbacillen gehandelt hatte, war nicht durch Cultur sichergestellt, allerdings sprach der färberische Nachweis und die Infectiosität des Materials für das Vorhandensein von Tuberkelbacillen; doch ist nach dem heutigen Stand der Kenntniss ron den säurefesten Bacillen nicht ausgeschlossen, dass es sich bei dem Befunde in den Regenwürmen um säurefeste Erdbakterien gehandelt hat.

${ }^{1}$ Möller, Therapeutische Monatshefte. November 1898 und Centralblatt für. Bakteriologie. Bd. XXV. S. 369.

"Chauveau, Akademie der Wissenschaften. Paris 1892. 
Auch in einer Veröffentlichung von Schneiderlin ${ }^{1}$ aus dem Schottelius'schen Institut ist die Möglichkeit nicht ganz von der Hand zu weisen, dass es sich um in der Erde gefundene säurefeste Bacillen handelte. Es waren tuberculöse und nicht tuberculöse Leichentheile getrennt vergraben, um die Lebensfähigkeit der Tuberkelbacillen und die Temperaturerhöhung bei der Verwesung im Erdboden zu prüfen. Nach langer Zeit wurden die Organe herausgegraben, und man fand die Tuberkelbacillen in den tuberculösen Organen in der Form verändert. Die Bacillen waren grösser und plumper geworden. Es fanden sich säurefeste Bacillen aber nicht nur in den ursprünglich tuberculösen Organen, sondern auch in den vergrabenen, welche nicht tuberculös waren. Das Auftreten der säurefesten Bacillen in den nicht tuberculösen Organen wurde dadurch erklärt, dass dieselben aus der Umgebung in die gesunden Organe gelangt seien. Auch hier kann man sich des Gedankens kaum erwehren, dass säurefeste Erdbakterien mit im Spiele gewesen sind.

Beim Studium der Verbreitung der säurefesten Bacillen kam es mir zuerst darauf an, festzustellen, ob dieselben ausnahmslos auf Timothee zu finden seien und dann, $o b$ sie eine allgemeine Verbreitung in der Ackererde hätten.

Ich untersuchte zuerst Timothee von 7 Feldstĩcken, welche in der Umgebung von Breslau von einander räumlich sehr weit getrennt lagen. In 3 Fällen konnten säurefeste Stäbchen nachgewiesen werden. Bei einer Probe schon nach 3 Tagen, bei den beiden anderen erst, nachdem die Thimotheeblätter 5 Wochen im Brütschrank gestanden hatten.

Demnach ist das Timotheegras nicht regelmässig der Träger der säurefesten Bacillen.

Des Weiteren wurde nun noch der Heustaub aus einer Scheune und aus dem Thierstall des Breslauer hygienischen Instituts untersucht. In beiden Fällen fanden sich nach 10 Tagen kurze, an beiden Enden verjüngte, säurefeste Stäbchen und vereinzelt auch solche, welche den Tuberkelbacillen täuschend ähnlich aussahen.

Wenn es nun nach den Möller'schen Befunden nahelag, eine Verbreitung der säurefesten Bacillen durch die Düngung anzunehmen, so war noch ein anderes Transportmittel möglich, nämlich der Timotheesamen, durch den die Bacillen bald auf dieses, bald auf jenes Feld mit dem Samen zugleich gesät werden könnten.

Thatsächlich fand ich auch leicht auf dem aus einer grossen Handlung hezogenen Thimotheesamen sïurefeste Bacillen.

' Schneiderlin, Ueber die Biologie des Tuberculoseerregers. Inang.-Diss. Freiburg i. B. 1897. 
Hierdurch wurde ich veranlasst, auch Roggen-, Gerste-, Weizen- und Haferkörner, sowie Erbsen zu untersuchen. Auf Gersten- und Weizenkörnern fanden sich die säurefesten Stäbchen ebenfalls, und wenn sie auf Roggen, Hafer und Erbsen nicht gefunden wurden, so schliesst der eine negative Untersuchungsbefund ihr Vorkommen natürlich nicht aus.

Interessant ist jedenfalls das Vorkommen auf der Gerste, da die Gerstengranne Trägerin der Aktinomykose sein soll und nach den Versuchen von Lubarsch durch intrarenale Injection von säurefesten Bacillen aktinomycesartige Bildungen hervorgerufen werden.

Kamen nun die säurefesten Bacillen durch Samenkörner oder Kuhdünger in die Erde, so mussten sie auch dort zu finden sein.

Es war wohl von vornherein anzunehmen, dass man dieselben nicht bei directer Aussaat auf Platten finden würde. Ich bediente mich daher eines Anreicherungsverfahrens. Es wurde Timotheegras zerschnitten, mit Wasser im Erlenmeyer'schen Kölbchen angesetzt und 4 Stunden im strömenden Dampf sterilisirt, dann mit etwa 1 Theelöffel Erde unter Umschütteln gemischt und in den Brütschrank gesetzt.

Von 13 Erdproben, die auf diese Weise untersucht wurden und stets von rerschiedenen Feldschlägen stammten, konnten in $\mathrm{zehn}$ säurefeste Bacilen nachgewiesen werden. Dieselben traten in dem Infus erst nach 4 bis 6 Tagen, oft auch erst nach 10 Tagen und länger auf. Sie waren bisweilen nur vereinzelt zu finden, öfter jedoch reichlich, so dass ganze Häufchen und in jedem Gesichtsfelde eine ganze Anzahl zu finden waren. Die Formen, unter denen die säurefesten Stäbchen auftraten, waren verschieden nicht nur bei den Gesammtproben, sondern auch in den einzelnen Proben, so dass in demselben Gesichtsfeld nicht nur deu Tuberkelbacillen gleiche, sondern auch plumpere und sehr kleine Formen auftraten. Die Bacillen fanden sich nicht vorwiegend in dem Infuswasser, sondern besonders häufig auf den aus dem Wasser hervorragenden feuchten, von Schimmelpilzen möglichst verschonten Blättern, eine Thatsache, die für dàs Auffinden der säurefesten Stäbchen im Infus von Wichtigkeit ist.

Im Anschluss an diese Versuche wurden nochmals zwölf andere verschiedene Bodenproben verarbeitet und zur Anreicherung gewöhnliches Heu- und Roggenstrohinfus benutzt. Es zeigte sich dabei, dass Roggenstroh für die Anreicherung nicht günstig ist. Durch die Anreicherung in Strohabkochung konnten nur bei drei, durch die in Heuabkochung bei sieben Proben säurefeste Bacillen nachgewiesen werden.

Die Herauszüchtung der säurefesten Bacillen aus der Erde gelingt nicht leicht. Das Plattenverfahren rersagte mir stets, da die Gelatine- 
204 Herr: Env Beitrag zUr Verbreitung Der sülrefesten Bacullen.

platten zu rasch verflüssigt, die Agarplatten durch Heubacillen zu schnell überwuchert wurden. Ebenso versagte auch die in zwei Fällen vorgenommene Thierimpfung. Die Fortsetzung dieser Versuche und die Anwendung besonderer Isolirungsmethoden musste ich aus äusseren Gründen auf eine spätere Zeit verschieben.

Aus den vorliegenden Versuchen geht jedenfalls hervor, dass die säurefesten Bacillen in der Natur sehr verbreitet sind. Sie finden sich nicht nur auf Gräsern und im Kuhdünger, sondern auch auf dem Timotheesamen und Getreidekörnern, sowie im Heustaub. Am meisten verbreitet sind sie jedoch in der dckererde, und es ist wohl wahrscheinlich, dass sie hier unter besonderen Verhältnissen eine grössere Rolle spielen, und die Erde das rorwiegende Element und das grosse Reservoir ist, aus dem die säurefesten Bacillen auf die Gräser, in den Kuhdünger, von dort auch in die Wiilch und nach einem mehr oder weniger complicirten Kreislauf wiederum zur Erde gelangen.

Ueber ihre Lebensthätigkeit als Erdbakterien und ihr Verhalten dem Thierkörper gegenüber habe ich Versuche in Aussicht genommen. 